\title{
Garcinol acts as an antineoplastic agent in human gastric cancer by inhibiting the PI3K/AKT signaling pathway
}

\author{
YUANYUAN ZHENG ${ }^{1}$, CHUANYONG GUO $^{2}$, XIAOPING ZHANG $^{1}$, XIAOLI WANG ${ }^{1}$ and A'HUO MA $^{1}$ \\ ${ }^{1}$ Department of Gastroenterology, Shaoxing People's Hospital (Shaoxing Hospital, Zhejiang University School of Medicine), \\ Shaoxing, Zhejiang 312000; ${ }^{2}$ Department of Gastroenterology, Shanghai Tenth People's Hospital, \\ Tongji University of Medicine, Shanghai 200072, P.R. China
}

Received June 20, 2019; Accepted April 15, 2020

DOI: $10.3892 / \mathrm{ol} .2020 .11585$

\begin{abstract}
Gastric cancer (GC) is one of the most common malignancies worldwide; however, treatment options other than surgery remain limited. Neoadjuvant chemotherapy has the potential to suppress of gastric tumorigenesis. Garcinol has been reported to exert inhibitory effects on the progression of numerous carcinomas. However, its effects in GC remain unclear. Therefore, the aim of the present study was to investigate the effects of garcinol on the proliferation, invasion and apoptosis of gastric carcinoma cells and then to explore the underlying mechanisms. Garcinol significantly decreased the proliferation and invasion of GC cells and increased apoptosis in a dose-dependent manner. Additionally, the expression of $\mathrm{AKT}^{\mathrm{p}-\mathrm{Thr308}}$, cyclin D1, Bcl-2, BAX, matrix metalloprotease (MMP-2) and MMP-9 in HGC-27 cells following treatment with garcinol. The results obtained in the present study suggested that garcinol may inhibit gastric tumorigenesis by suppressing the PI3K/AKT signaling pathway.
\end{abstract}

\section{Introduction}

Gastric cancer (GC) is a malignant tumor of epithelial origin and is the third most common cancer worldwide (1). Currently, a combination of surgery and perioperative adjuvant or neoadjuvant therapy are the mainstay of treatment for GC, but depend on the disease stage and pathological type $(2,3)$. Although there has been a decline in the incidence of GC in recent decades due to progress in clinical interventions $(4,5)$, the high morbidity and mortality associated with the disease pose challenges to public health. Studies suggest

Correspondence to: Dr A'Huo Ma or Dr Xiaoli Wang, Department of Gastroenterology, Shaoxing People's Hospital (Shaoxing Hospital, Zhejiang University School of Medicine), 568 North Zhongxing Road, Shaoxing, Zhejiang 312000, P.R. China

E-mail:maahuo@sohu.com

E-mail:wxli1971@163.com

Key words: garcinol, gastric cancer, proliferation, invasion, apoptosis, PI3K, AKT that multiple genetic and environmental factors impact the risk and progression of GC $(4,6)$. The pathways underlying the pathogenesis of GC have not yet been fully elucidated, and a deeper understanding of the dysregulation involved in the intracellular signaling pathways may aid the development of novel therapeutic strategies.

The activation of protein kinase B (AKT) by phosphatidylinositol-3-kinase (PI3K) is required for cell proliferation, invasion, apoptosis and angiogenesis, and is associated with the progression of neoplasms (7-9). Several components of the PI3K/AKT signaling pathway may serve as potential therapeutic targets in a number of human tumors, including GC and breast and lung cancer (8,10-12). Cell cycle regulator D1 (cyclin D1) is activated by mammalian target of rapamycin (mTOR) via phosphorylation of AKT at either serine 473 or threonine 308 and is important in the G1/S transition of tumor cells $(13,14)$. Upregulation of cyclin D1 may lead to shortening of the cell cycle and increased proliferation of tumor cells, thereby expediting tumor progression. Matrix metalloproteinases (MMPs) promote the degradation of the extracellular matrix and therefore affect the invasion and metastasis of cancer cells. The production of MMPs has been shown to be regulated by the PI3K/AKT signaling pathway $(15,16)$. Activation of the PI3K/AKT signaling pathway inhibits apoptosis via the expression of specific downstream proteins, including B-cell lymphoma-2 (Bcl-2) and Bcl-2 associated $\mathrm{X}$ protein $(\mathrm{BAX})(7,17)$. Therefore, noveltherapeutic agents that specifically target the PI3K/AKT signaling pathway may improve GC treatment.

Garcinol (Fig. 1A), a polyisoprenylated benzophenone derived from Garcinia indica exhibits anti-inflammatory, acetyltransferase inhibitory, antioxidant, and anticancer effects by regulating several signaling pathways (18-20). Previous studies have shown the therapeutic potential of garcinol for gastric ailments, such as ulcers $(18,21)$. Additionally, the anticancer effects of garcinol have been demonstrated in a number of carcinomas in vitro and in vivo. Specifically, garcinol exerted inhibitory effects in colon and prostate cancer via the PI3K/AKT signaling pathway $(22,23)$. Additionally, garcinol decreased tumor cell proliferation, angiogenesis and cell cycle progression, and increased apoptosis in oral cancer (24). The results of the aforementioned studies suggest that garcinol may serve as a potential antineoplastic agent $(20,24)$. However, 
the effects of garcinol in GC and its underlying mechanism remain unclear.

The present study aimed to investigate the effects of garcinol on the proliferation, invasion, and apoptosis of the GC cell line HGC-27 and to further explore the associated mechanisms. The results revealed that garcinol decreased colony formation ability, viability, migration and invasion in a dose-dependent manner. Moreover, garcinol promoted apoptosis. Further investigation revealed that, garcinol exerted its inhibitory effects on GC cells by regulating the PI3K/AKT signaling pathway.

\section{Materials and methods}

Cell culture. The human GC cell line, HGC-27 (cat no. TCHu 22) was obtained from The Cell Bank of Type Culture Collection of the Chinese Academy of Sciences and was tested for mycoplasma and authenticated by STR profiling. The cells were cultured in RPMI-1640 medium (Sigma-Aldrich; Merck KGaA) supplemented with $10 \%$ fetal bovine serum (FBS; Sigma-Aldrich; Merck KGaA) and $1 \%$ penicillin-streptomycin (PS; Beyotime Institute of Biotechnology) at $37^{\circ} \mathrm{C}$ in a humidified atmosphere containing $5 \% \mathrm{CO}_{2}$. Garcinol was obtained from Sigma-Aldrich (Merck KGaA) and SC79 was purchased from MedChemExpress.

Cell viability. HGC-27 $\left(2 \times 10^{4}\right.$ cells $\left./ \mathrm{ml}\right)$ cells were seeded in $100 \mu \mathrm{l}$ medium per well in a 96 -well plate. Cells were incubated for $6 \mathrm{~h}$ and subsequently treated with increasing concentrations of garcinol $[0,2.5,5,10,20,40,80$ and $160 \mu \mathrm{M}$ in RPMI-1640 medium supplemented with $10 \%$ FBS, $1 \%$ PS and $50 \mathrm{mM}$ dimethyl sulfoxide (DMSO)] for $48 \mathrm{~h}$. A total of $10 \mu 1 \mathrm{MTT}$ solution $(5 \mathrm{mg} / \mathrm{ml}$ in PBS; Beyotime Institute of Biotechnology) was added to each well and the cells were incubated for an additional $4 \mathrm{~h}$ at $37^{\circ} \mathrm{C}$. The medium was then discarded and the purple formazan crystals were dissolved using $150 \mu 1$ of DMSO. After 10 min of oscillation in dark, the absorbance was read at a wavelength of $570 \mathrm{~nm}$ using a SpectraMax Plus 384 plate reader (Molecular Devices, -LLC). The median lethal concentration (LC50) was calculated using SPSS software (version 24.0; IBM Corp.).

Clone formation assay. HGC-27 cells were seeded at a density of $1 \times 10^{3}$ cells/well in a 6 -well plate. Cells were then treated with $5 \mu \mathrm{M}$ garcinol in serum-containing medium, or an equal volume of DMSO dissolved in medium as a control, for 14 days. The cells were subsequently fixed using $10 \%$ formalin for $20 \mathrm{~min}$ and stained with $0.1 \%$ crystal violet for $5 \mathrm{~min}$ at room temperature. Colonies containing $>50$ cells were counted under a light microscope (Eclipse TS100; Nikon Corporation).

Wound healing assay. HGC-27 cells were cultured in 6-well plates to $80 \%$ confluence and then serum starved for $24 \mathrm{~h}$. A $100 \mu 1$ sterile pipet tip was used to create scratches in the confluent cell monolayers and the cells were gently washed with PBS. The cells were incubated with garcinol $(0,10,20$, or $40 \mu \mathrm{M}$ in RPMI-1640 medium supplemented with $10 \%$ FBS and $1 \%$ PS) and cells were cultured for an additional $48 \mathrm{~h}$. An optical microscope (Eclipse TS100; Nikon Corporation) was used to image the wound at 0 and $48 \mathrm{~h}$ and the width of the wound was measured using Image-Pro Plus software (version 6.0; Media Cybernetics, Inc.).

Matrigel invasion assay. Transwell chambers $(8.0-\mu \mathrm{m}$ pore size; Corning, Inc.) coated with Matrigel (Corning, Inc.) were used to evaluate the effect of garcinol on the invasiveness of HGC-27 cells. HGC-27 cells $\left(1 \times 10^{5} / \mathrm{ml}\right)$ were seeded into the upper chambers of the inserts in $200 \mu \mathrm{l}$ serum-free RPMI-1640, while different concentrations of garcinol $(0,10$, 20 or $40 \mu \mathrm{M}$ in RPMI-1640 supplemented with $10 \%$ FBS and $1 \%$ PS) was added to the lower chambers. Cells were cultured for $48 \mathrm{~h}$ at $37^{\circ} \mathrm{C}$ in a humidified atmosphere containing $5 \%$ $\mathrm{CO}_{2}$. The invading cells were then fixed and stained using the same conditions described for the clone formation assays. The stained HGC-27 cells were subsequently imaged and counted.

Flow cytometry and cell cycle analysis. HGC-27 cells were seeded in 6-well plates and cultured to $60 \%$ confluence. The cells were subsequently treated with garcinol $(0,10,20$ and $40 \mu \mathrm{M}$ in RPMI-1640 medium supplemented with $10 \% \mathrm{FBS}$ and $1 \% \mathrm{PS}$ ) for an additional $48 \mathrm{~h}$. The cells were harvested, suspended in cold PBS and centrifuged at $114 \mathrm{x}$ g. The cells were then resuspended and centrifuged two more times. Annexin V-FITC/PI (Beyotime Institute of Biotechnology) double staining was performed according to the manufacturer's instructions. The cells were incubated for $20 \mathrm{~min}$ at room temperature in the dark and apoptosis was analyzed using a flow cytometer. For cell cycle analysis, HGC-27 cells were treated as aforementioned, collected and fixed with $70 \%$ ethanol at $4^{\circ} \mathrm{C}$ overnight. Cells were washed with cold PBS and incubated with propidium iodide for $30 \mathrm{~min}$ at room temperature in the dark. ModFit LT software (version 5.0; www.vsh.com) was used to analysis the cell cycle transition of HGC-27 cells treated with increasing concentrations of garcinol.

Hoechst 33258 staining. HGC-27 cells were seeded in 96-well plates and incubated with garcinol $(0,10,20$, and $40 \mu \mathrm{M})$ for $48 \mathrm{~h}$. The cells were subsequently fixed with $4 \%$ polyoxymethylene for $20 \mathrm{~min}$ at room temperature and washed twice with PBS. The cells were stained with $10 \mu \mathrm{g} / \mathrm{ml}$ Hoechst 33258 for $5 \mathrm{~min}$ in the dark and washed twice with PBS. The nuclear morphology of the HGC-27 cells was observed using a fluorescence microscope (200x magnification).

Western blotting. HGC-27 cells were treated with garcinol $(0,10,20$ and $40 \mu \mathrm{M})$ for $48 \mathrm{~h}$ and subsequently harvested. The total cellular protein was extracted using radio-immunoprecipitation assay lysis buffer (Beyotime Institute of Biotechnology) at $4^{\circ} \mathrm{C}$. The lysates $(10 \mu$ (protein per lane, BCA assay) separated via SDS-PAGE on a $10 \%$ gel and transferred onto nitrocellulose membranes. After blocking with 5\% non-fat powdered milk for $60 \mathrm{~min}$ at room temperature, the membranes were incubated overnight at $4^{\circ} \mathrm{C}$ with the following primary antibodies: Anti-PI3K (cat. no. 4249; 1:1,000; Cell Signaling Technology, Inc.), anti-AKT (cat. no. ab32505; 1:1,000; Abcam), anti-AKT ${ }^{\text {-Thr308 }}$ (cat. no. ab38449; 1:1,000, Abcam),

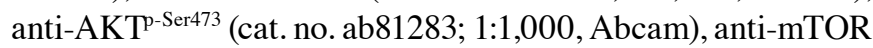
(cat. no. ab2732; 1:1,000; Abcam), anti-mTOR ${ }^{\mathrm{p}-\mathrm{Ser} 2448}$ 
A

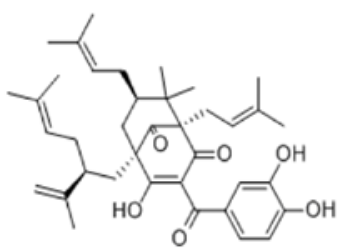

C

HGC-27

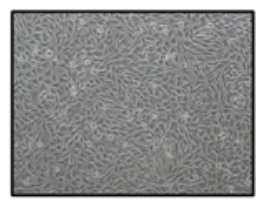

0

D

HGC-27

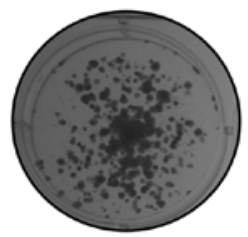

0

E

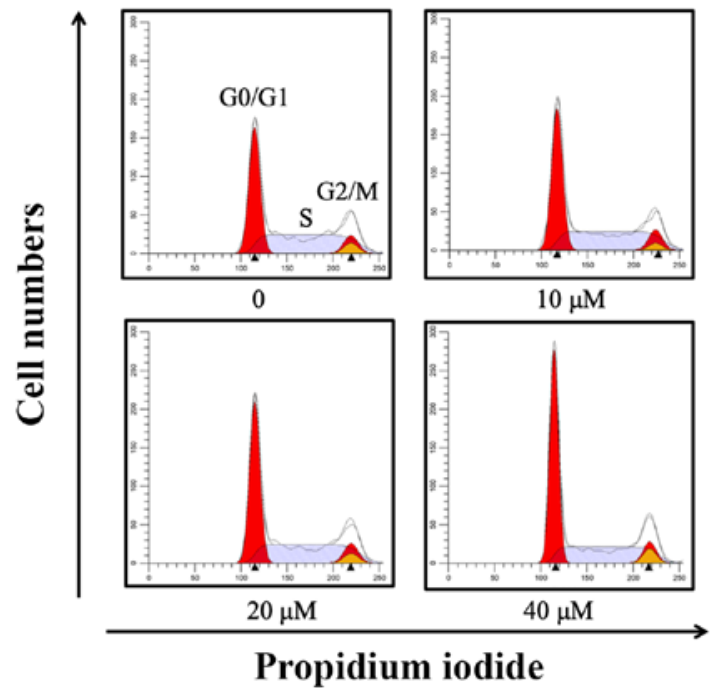

B

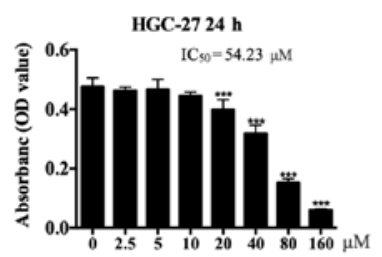

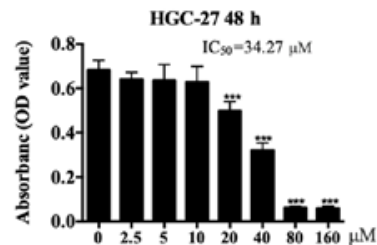

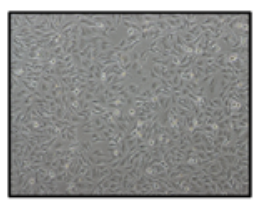

$10 \mu \mathrm{M}$

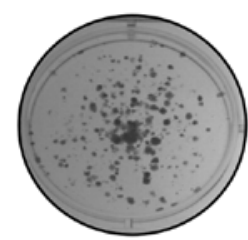

$10 \mu \mathrm{M}$

$20 \mu \mathrm{M}$

F

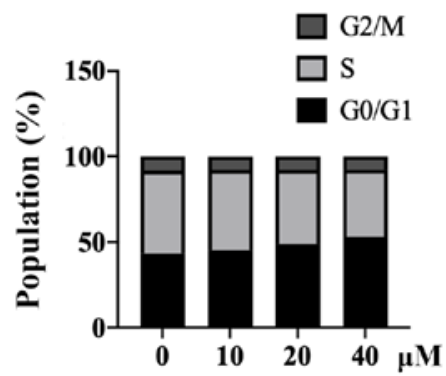

Figure 1. Garcinol decreases the proliferation and viability of gastric cancer cells. (A) Chemical structure of garcinol. (B) Effects of garcinol on the viability of HGC-27 cells at 24 and $48 \mathrm{~h}$ as determine by the MTT assay. ${ }^{* * *} \mathrm{P}<0.005 \mathrm{vs} .0 \mu \mathrm{M}$. (C) Morphological alterations in HGC-27 cells after treatment with garcinol for 48 h. (D) Clonogenic variation in HGC-27 cells after treatment with garcinol for 48 h. (E) HGC-27 cells treated with garcinol for 48 h exhibited cell cycle arrest. (F) Effect of garcinol on cell cycle arrest at $48 \mathrm{~h}$ was analyzed. Each experiment was performed in triplicate. OD, optical density.

(cat. no. 5536; 1:1,000; Cell Signaling Technology, Inc.), anti-cyclin D1 (cat. no. 60186-1-Ig; 1:1,000; ProteinTech, Inc.), anti-Bcl-2 (cat. no. 15071; 1:1,000; Cell Signaling Technology, Inc.), anti-BAX (cat. no. 14796; 1:1,000; Cell Signaling Technology, Inc.), anti-MMP-2 (cat. no. ab97779; 1:1,000; Abcam), anti-MMP-9 (cat. no. ab76003; 1:1,000; Abcam) and anti- $\beta$-actin (cat. no. 3700; 1:1,000; Cell Signaling Technology, Inc.). The membranes were then washed three times with $1 \%$ Tris-buffered saline/Tween-20 and incubated with the appropriate horseradish peroxidase secondary antibodies (cat. no. A21020 and A21010; 1:1,000; Abbkine Scientific Co., Ltd.) for $4 \mathrm{~h}$ at $4^{\circ} \mathrm{C}$. The protein bands were visualized using the BeyoECL kit (Beyotime Institute of Biotechnology). $\beta$-actin was used as the loading control.
Statistical analysis. Data are expressed as the mean \pm SD of three independent experiments. Statistical analyses were performed using GraphPad Prism software (version 7.0; GraphPad Software, Inc.). One-way analysis of variance with Tukey's post hoc test was used for the statistical analysis of the groups. $\mathrm{P}<0.05$ was considered to indicate a statistically significant difference.

\section{Results}

Garcinol decreases the proliferation and viability of GC cells. The proliferation and viability of HGC-27 cells were significantly suppressed by garcinol. HGC-27 cells treated with a low concentration of garcinol exhibited similar optical density 
A
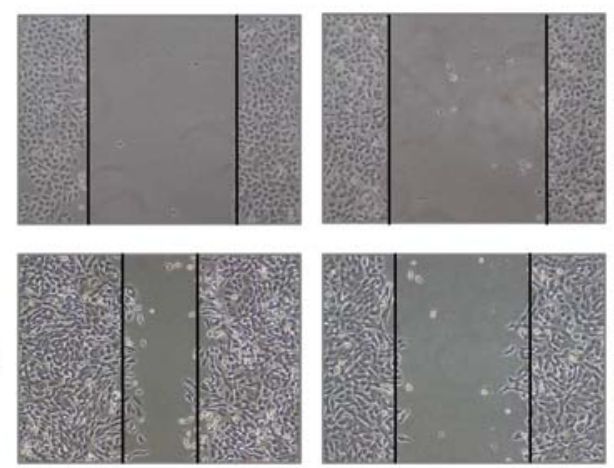

$24 \mathrm{~h}$
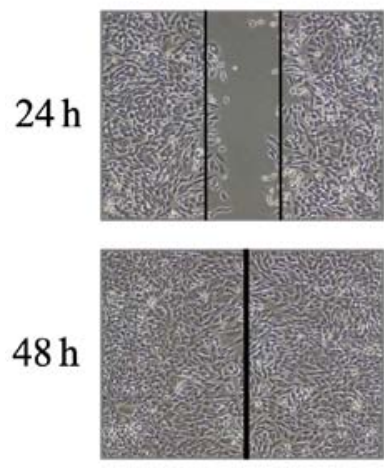

0

B

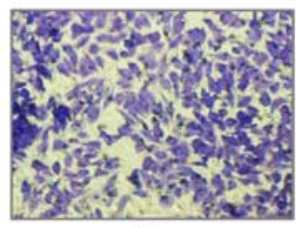

0

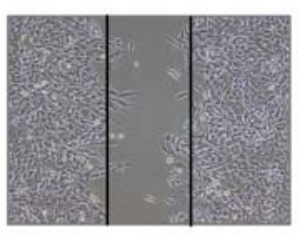

$10 \mu \mathrm{M}$

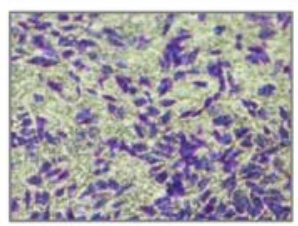

$10 \mu \mathrm{M}$
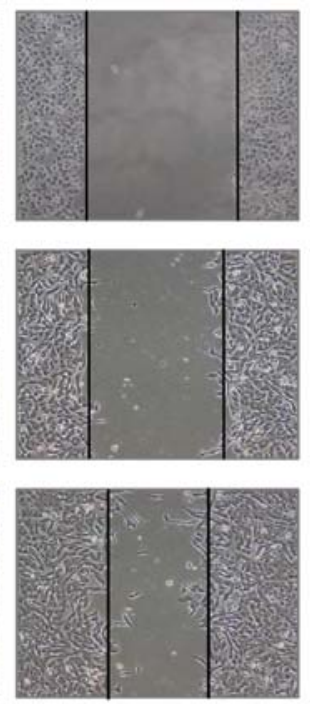

$20 \mu \mathrm{M}$

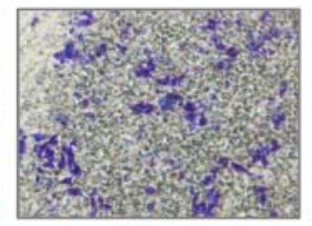

$20 \mu \mathrm{M}$
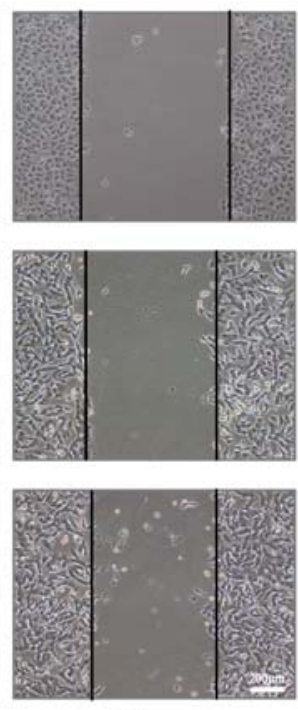

$40 \mu \mathrm{M}$

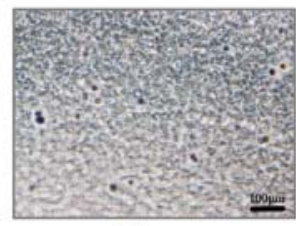

$40 \mu \mathrm{M}$

C
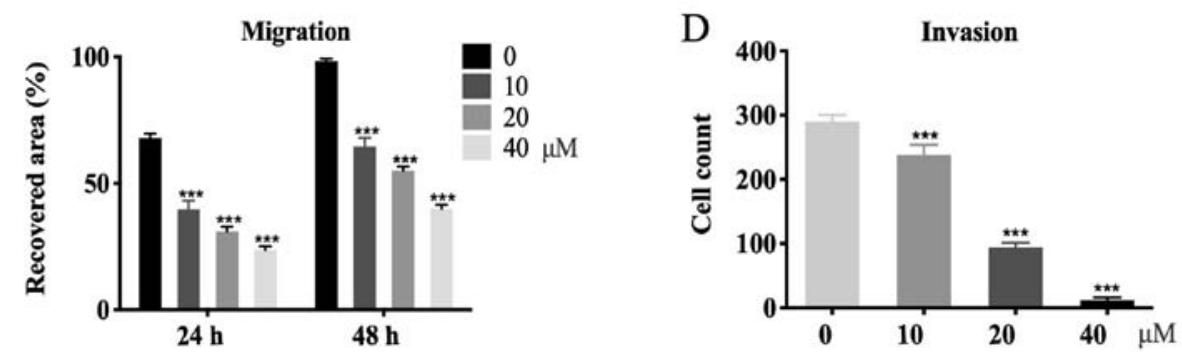

Figure 2. Garcinol inhibits the migration and invasion of gastric cancer cells. (A) HGC-27 cells were treated with garcinol at a concentration of 0 , 10,20 and $40 \mu \mathrm{M}$. Images were captured at 0,24 and $48 \mathrm{~h}$ using an optical microscope. Scale bar, $200 \mu \mathrm{m}$. (B) Matrigel-coated Transwell chambers were used to examine the invasiveness capability of HGC-27 cells following garcinol treatment $(0,10,20$ and $40 \mu \mathrm{M})$ for $48 \mathrm{~h}$. Scale bar, $100 \mu \mathrm{m}$. (C) Width of the wound was measured using Image-Pro Plus software (version 6.0). ${ }^{* * *} \mathrm{P}<0.0050 \mu \mathrm{M}$. (D) Invading cells were imaged and counted. Each experiment was performed in triplicate and results were analyzed by one-way analysis of variance with Tukey's post hoc test. ${ }^{* * *} \mathrm{P}<0.005$ vs. $0 \mu \mathrm{M}$. Data are presented as the mean $\pm \mathrm{SD}$.

values to their respective negative controls (Fig. 1B and C). However, the optical density values of HGC-27 cells treated with higher doses of garcinol were significantly reduced (T-test: $0.50 \pm 0.042,20 \mu \mathrm{M}, \mathrm{P}<0.001 ; 0.32 \pm 0.034,40 \mu \mathrm{M}$, $\mathrm{P}<0.001 ; 0.06 \pm 0.005,80 \mu \mathrm{M}, \mathrm{P}<0.001 ; 0.06 \pm 0.009,160 \mu \mathrm{M}$, $\mathrm{P}<0.001$ ). The median lethal concentration (LC50) of garcinol treatment in HGC-27 cells was $34.27 \mu \mathrm{M}$. HGC-27 cells treated with garcinol $(0,10,20$ and $40 \mu \mathrm{M})$ for $48 \mathrm{~h}$ displayed a marked decrease in cell growth (Fig. 1B and C). Furthermore, garcinol significantly decreased the colony formation ability of HGC-27 cells in a dose-dependent manner (Fig. 1D). In order to further investigate the effects of garcinol on the cell cycle transition of HGC-27 cells, cell cycle analysis was performed. The percentage of cells in the G0/G1 phase was significantly increased (ANOVA: $45.33 \pm 0.182,10 \mu \mathrm{M}, \mathrm{P}<0.05$; 48.86 $\pm 1.148,20 \mu \mathrm{M}, \mathrm{P}<0.001 ; 53.11 \pm 0.769,40 \mu \mathrm{M}, \mathrm{P}<0.001)$ while the percentage of cells in the $\mathrm{S}$ phase was decreased
(ANOVA: 46.69 $\pm 0.201,10 \mu \mathrm{M}, \mathrm{P}<0.05 ; 43.15 \pm 1.151,20 \mu \mathrm{M}$, $\mathrm{P}<0.001 ; 38.91 \pm 0.757,40 \mu \mathrm{M}, \mathrm{P}<0.001)$ in garcinol-treated cells compared with controls $(43.39 \pm 0.350,0 \mu \mathrm{M}, \mathrm{G} 0 / \mathrm{G} 1$ phase; $48.66 \pm 0.424,0 \mu \mathrm{M}, \mathrm{S}$ phase; Fig. $1 \mathrm{E}$ and F).

Garcinol inhibits the migration and invasion of GC cells. Garcinol exerted a dose-dependent inhibitory effect on migration and invasion in HGC-27 cells (Fig. 2A and B). Wound-healing assays were performed to investigate the effects of garcinol on the migration of HGC-27 cells. Compared with the control group $(98.3 \pm 0.9 \%$; Fig. $2 \mathrm{C})$ the percentage wound closure exhibited a significant decrease with increasing garcinol concentrations after $48 \mathrm{~h}$ of treatment: 64.6 $\pm 2.75 \%(10 \mu \mathrm{M} ; \mathrm{P}<0.001), 55.1 \pm 1.3 \%(20 \mu \mathrm{M}$; $\mathrm{P}<0.001), 40.0 \pm 1.2 \%(40 \mu \mathrm{M} ; \mathrm{P}<0.001$; Fig. 2C). A similar trend was observed at the $24-\mathrm{h}$ time point $(\mathrm{P}<0.001$; Fig. $2 \mathrm{C})$. Matrigel-coated Transwell chambers were used to evaluate the 
A

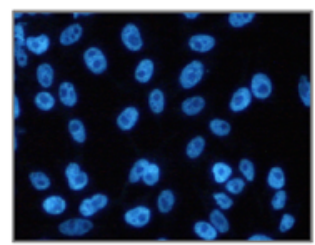

0

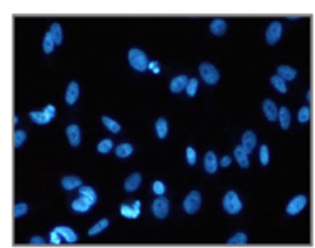

$20 \mu \mathrm{M}$

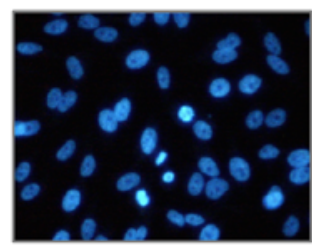

$10 \mu \mathrm{M}$

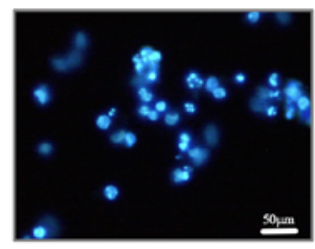

$40 \mu \mathrm{M}$
B

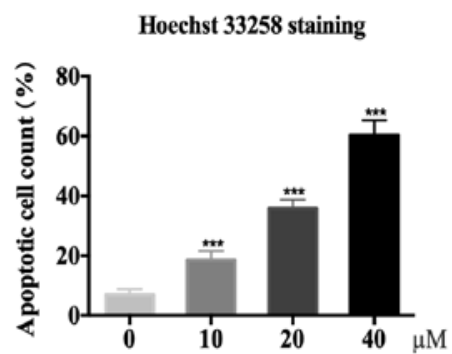

C

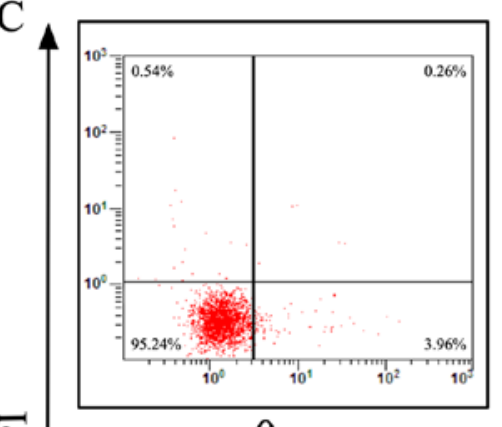

$\bar{a}$

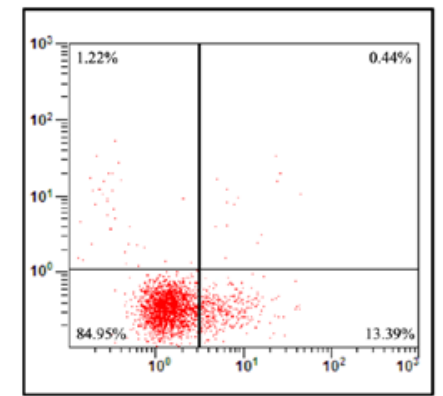

$20 \mu \mathrm{M}$

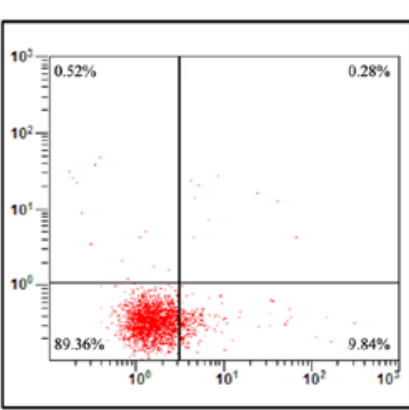

$10 \mu \mathrm{M}$

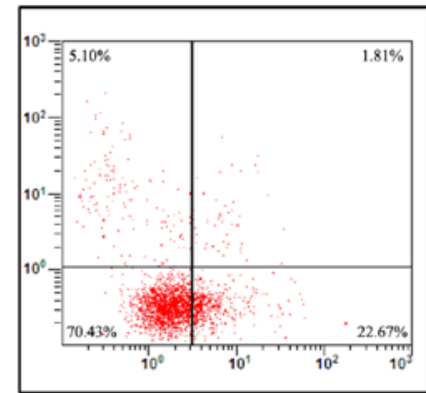

$40 \mu \mathrm{M}$
D

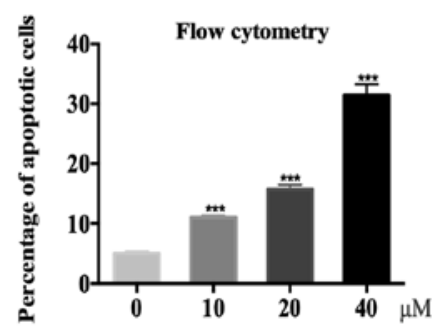

Figure 3. Garcinol induces apoptosis of gastric cancer cells. (A) HGC-27 cells were treated with garcinol (0, 10,20 and $40 \mu \mathrm{M})$ for $48 \mathrm{~h}$ and stained with Hoechst 33258. The cells were subsequently imaged using a fluorescence microscope. (B) Cells with condensed and fragmented cell nuclei were counted to assess the impact of garcinol on cell apoptosis. ${ }^{* * *} \mathrm{P}<0.005 \mathrm{vs} .0 \mu \mathrm{M}$. (C) Annexin V-FITC/PI staining and flow cytometry analysis were used to assess the apoptotic ratio of HGC-27 cells treated with garcinol $(0,10,20$ and $40 \mu \mathrm{M})$. (D) Quantitative analysis for flow cytometry. ${ }^{* * *} \mathrm{P}<0.005$ vs. $0 \mu \mathrm{M}$. Each experiment was performed in triplicate. PI, propidium iodide.

inhibitory effects of garcinol on the invasion of HGC-27 cells. The control group exhibited the highest number of invading cells $(255.3 \pm 13.0)$. This number significantly decreased with increasing concentrations of garcinol at $48 \mathrm{~h}: 196.7 \pm 13.3$ $(10 \mu \mathrm{M} ; \mathrm{P}<0.001), 83.3 \pm 6.3(20 \mu \mathrm{M} ; \mathrm{P}<0.001)$ and $12.0 \pm 3.2$ (40 $\mu \mathrm{M} ; \mathrm{P}<0.001$; Fig. 2D).

Garcinol induces apoptosis of GC cells. Garcinol was found to induce the programmed cell death of HGC-27 cells. Hoechst 33258 staining was used to observe nuclear changes in HGC-27 cells. Cells with condensed and fragmented nuclei were considered apoptotic (Fig. 3A). The number of apoptotic HGC-27 cells increased from $6.9 \pm 1.52$ in the control group to $18.6 \pm 2.46(\mathrm{P}<0.001), 35.9 \pm 2.34(\mathrm{P}<0.001)$ and $60.3 \pm 4.10$ $(\mathrm{P}<0.001)$ in cells treated with 10,20 and $40 \mu \mathrm{M}$ garcinol for 48 h, respectively (Fig. 3B). The annexin V-FITC/PI staining assay revealed a similar trend. In particular, the number of early apoptotic HGC-27 cells (annexin $\mathrm{V}^{+} / \mathrm{PI}^{-}$) significantly increased with garcinol concentrations as follows: $11.1 \pm 0.32 \%$ (10 $\mu \mathrm{M} ; \mathrm{P}<0.001), 15.8 \pm 0.67 \%(20 \mu \mathrm{M} ; \mathrm{P}<0.001), 31.5 \pm 1.81 \%$ (40 $\mu \mathrm{M} ; \mathrm{P}<0.001$; Fig. $3 \mathrm{C}$ and D).

Garcinol down-regulates the activation of the PI3K/AKT signaling pathway and its downstream effectors. Western blotting was used to determine the concentration-dependent effects of garcinol on the expression of several key proteins in 

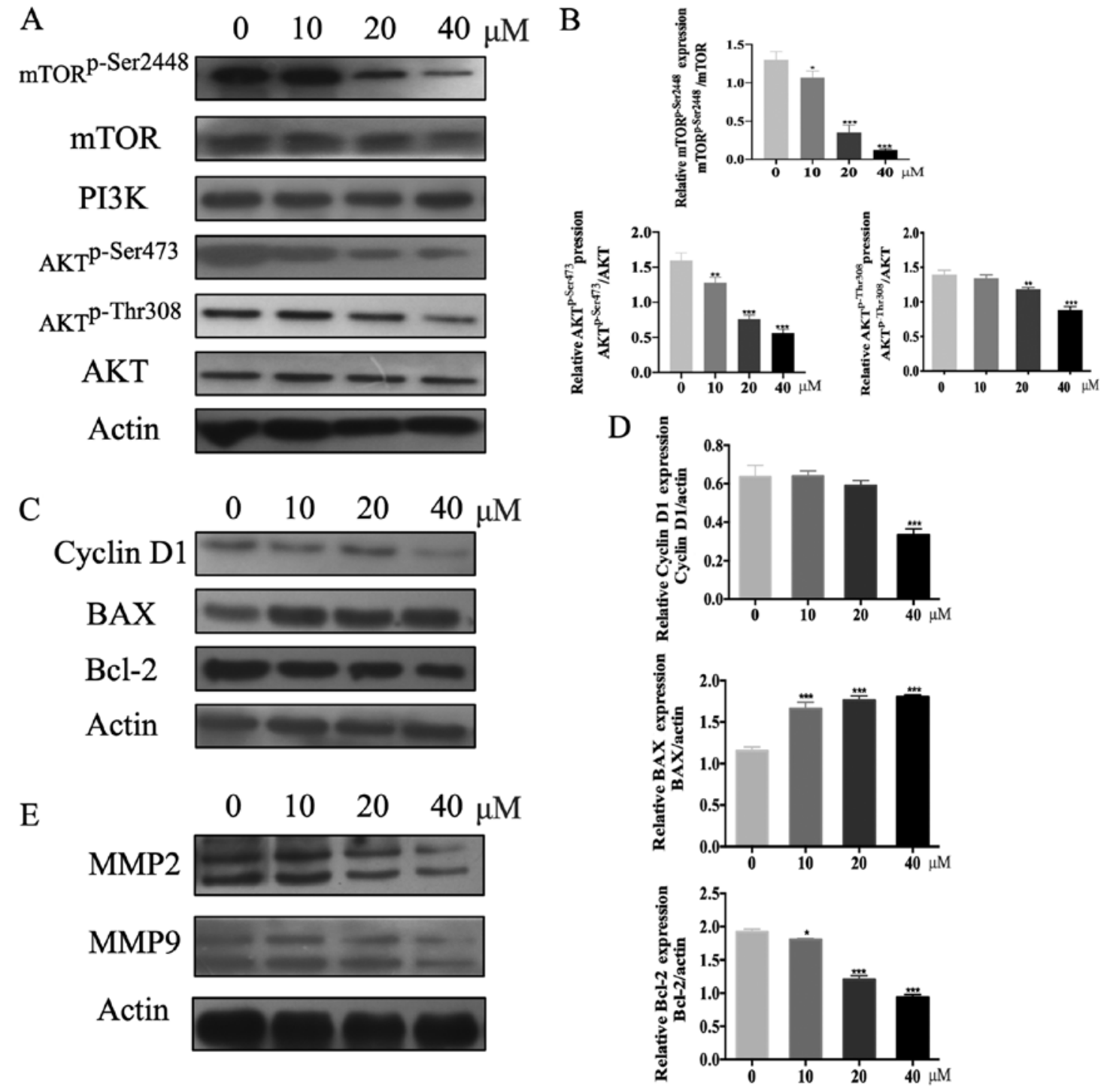

$\mathrm{F}$
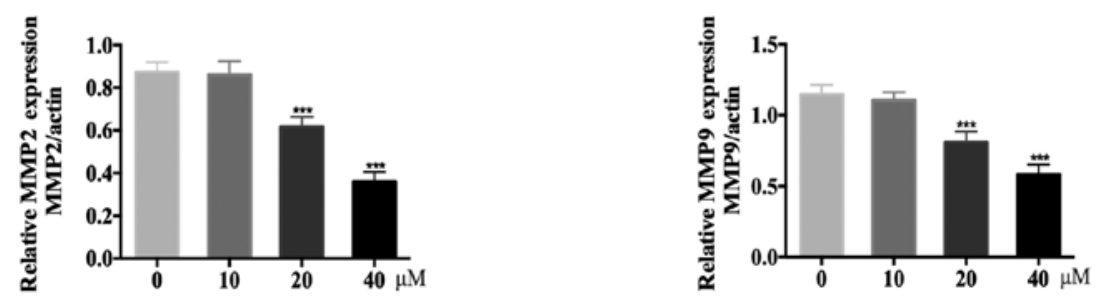

Figure 4. Garcinol downregulateds PI3K/AKT and its downstream signaling pathway. (A) HGC-27 cells were treated with garcinol $(0,10,20$ and $40 \mu \mathrm{M})$ for $48 \mathrm{~h}$ and western blotting was used to determine the protein expression levels of PI3K, AKT, AKT ${ }^{\text {-Thr308 }}, \mathrm{AKT}^{\mathrm{Ser} 473}, \mathrm{mTOR} \mathrm{mTOR}^{\mathrm{p}-\mathrm{Ser} 2448}$ and $\beta$-actin (B) Quantitative analysis for the western blotting. The protein expression levels of PI3K, AKT, AKT ${ }^{\text {-Thr308 }}, \mathrm{AKT}^{\mathrm{Ser} 473}$, mTOR, mTOR $^{\mathrm{p}-\mathrm{Ser} 2448}$ and $\beta$-actin in each dose group $(10,20$ and $40 \mu \mathrm{M})$ were compared with those in the no drug treatment group $(0 \mu \mathrm{M})$. ${ }^{*} \mathrm{P}<0.05,{ }^{* * *} \mathrm{P}<0.01$ and ${ }^{* * *} \mathrm{P}<0.005$ vs. $0 \mu \mathrm{M}$. (C) HGC-27 cells were treated with garcinol $(0,10,20$ and $40 \mu \mathrm{M})$ for $48 \mathrm{~h}$ and the protein expression levels of cyclin D1, BAX, Bcl-2 and $\beta$-actin were determined by western blotting. (D) Semi-quantitative analysis was performed to compare the protein expression levels of cyclin D1, BAX, Bcl-2 and $\beta$-actin in each dose group $(10,20$ and $40 \mu \mathrm{M})$ with those in the no drug treatment group $(0 \mu \mathrm{M}){ }^{*} \mathrm{P}<0.05$ and ${ }^{* * * *} \mathrm{P}<0.005$ vs. $0 \mu \mathrm{M}$. (E) Western blotting was used to determine the protein expression levels of MMP-2, MMP-9 and $\beta$-actin in HGC-27 cells under the treatment of garcinol $(0,10,20$ and $40 \mu \mathrm{M})$ for 48 h. (F) Protein expression levels of MMP-2, MMP-9 and $\beta$-actin in each dose group $(10,20$ and $40 \mu \mathrm{M})$ were quantitatively analyzed and compared with those in the no drug treatment group $(0 \mu \mathrm{M}) .{ }^{* * *} \mathrm{P}<0.005$ vs. $0 \mu \mathrm{M}$. Each experiment was performed in triplicate. MMP, matrix metalloprotease.

the PI3K/AKT signaling pathway in HGC-27 cells. Garcinol significantly inhibited the levels of $\mathrm{AKT}^{\mathrm{p}-\mathrm{Thr} 308}$ and $\mathrm{AKT}^{\mathrm{p} \text {-ser473 }}$ in HGC-27 cells, in a dose-dependent manner, while PI3K and total AKT levels were not affected (Fig. 4A and B). Additionally, garcinol significantly reduced the phosphorylation of mTOR, while the expression of total mTOR remained stable $(\mathrm{P}<0.05$; Fig. $4 \mathrm{~A}$ and $\mathrm{B})$. Cyclin $\mathrm{D} 1$ levels were then examined to further evaluate the impact of garcinol on the G1/S transition of GC cells. Garcinol treatment was found to decrease cyclin D1 levels in HGC-27 cells in a dose-dependent manner ( $\mathrm{P}<0.05$; Fig. 4C and D). Garcinol also significantly reduced the expression of the proteolytic enzymes MMP-2 and MMP-9 ( $<<0.05$; Fig. 4E and F), which are considered to be crucial for the malignant invasion and metastasis of 
A

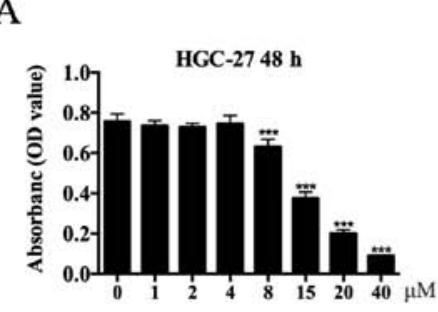

B

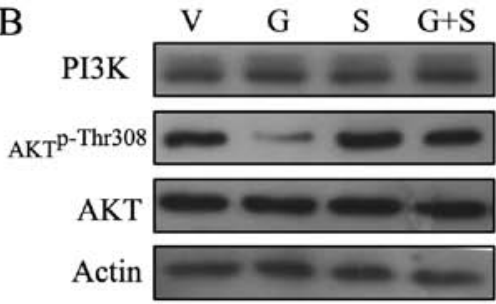

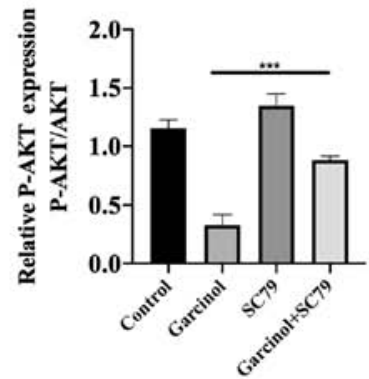

C
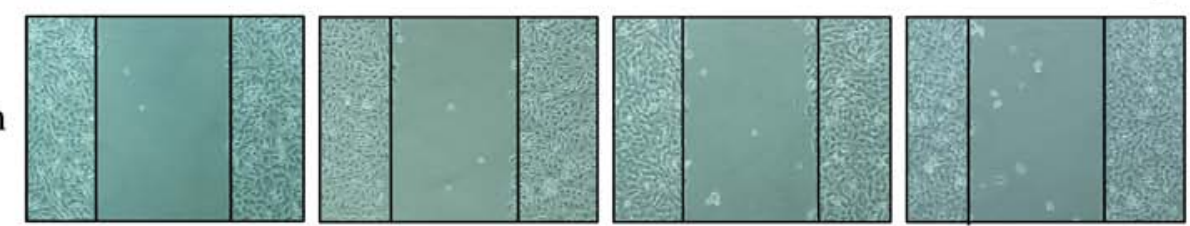

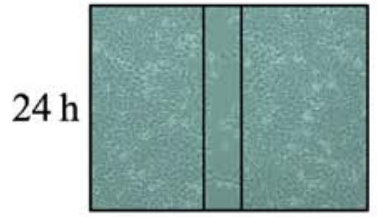

Control

D

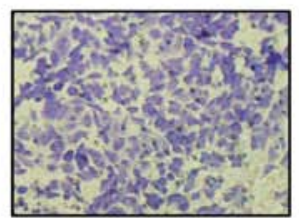

Control

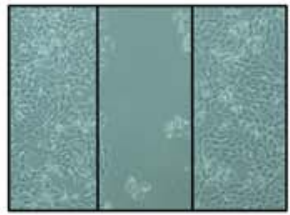

Garcinol

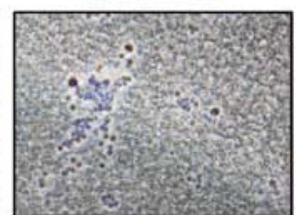

Garcinol

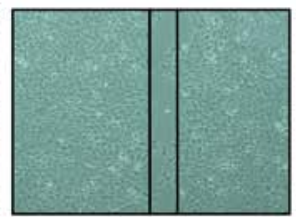

SC79

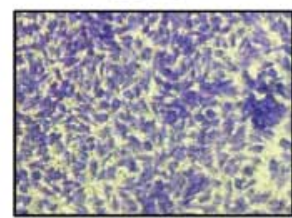

SC79

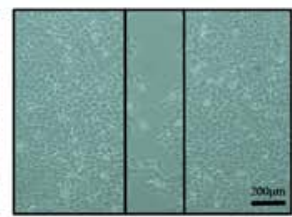

Garcinol+SC79

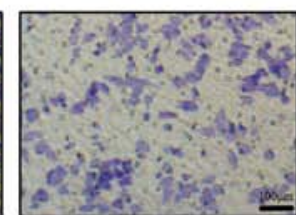

Garcinol +SC79
E

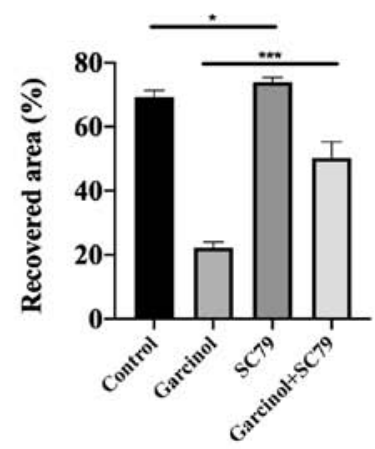

F

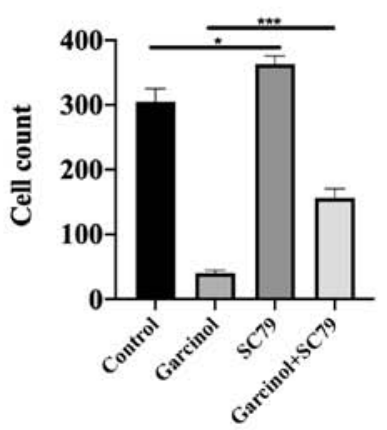

Figure 5. SC79, a specific AKT agonist, rescues the inhibitory effect of garcinol on the proliferation and invasion of HGC-27 cells. (A) Safe effective dose of SC79 on HGC-27 cells at $48 \mathrm{~h}$ was measured by MTT assay. The absorbance of each dose group $(1,2,4,8,15,20$ and $40 \mu \mathrm{M})$ was compared with no SC79 treatment group $(0 \mu \mathrm{M}){ }^{* * * *} \mathrm{P}<0.005$ vs. $0 \mu \mathrm{M}$. (B) Western blotting was performed to estimate the protein expression levels of PI3K, AKT, AKTp-Thr308 and $\beta$-actin in HGC-27 cells at $48 \mathrm{~h} .{ }^{* * * *} \mathrm{P}<0.005$, as indicated. (C) Width of the wound was measured at 0 and $24 \mathrm{~h}$. Scale bar, $200 \mu \mathrm{m}$. (D) A Transwell invasion assay was performed to investigate the invasion of HGC-27 cells in the different groups at $48 \mathrm{~h}$. Scale bar, $100 \mu \mathrm{m}$. (E) Recovered area of each group was compared with vacant control group at $24 \mathrm{~h}$. $\mathrm{P}<0.05$ and ${ }^{* * *} \mathrm{P}<0.005$, as indicated. (F) Invaded cell counts of each intervention group were compared with the vacant control group at $48 \mathrm{~h}$. "P<0.05 and ${ }^{* * * *} \mathrm{P}<0.005$, as indicated. V, vacant control; G, garcinol; S, SC79; G+S, garcinol+SC79.

carcinomas $(15,16)$. Furthermore, an increase in expression of the pro-apoptotic BAX protein, together with a decrease in expression of the anti-apoptotic Bcl-2 protein, was observed $(\mathrm{P}<0.05$; Fig. 4C and $\mathrm{D})$.

Specific AKT agonist SC79 rescues garcinol-induced inhibitory effects in HGC-27 cells. The specific AKT agonist SC79 (25) was used to rescue the garcinol-induced inhibitory effects on HGC-27 cell proliferation, invasion and apoptosis. The MTT assay was performed to identify the most effective dose of SC79 (Fig. 5A). Western blotting was used to detect the expression levels of key proteins in the PI3K/AKT signaling pathway. Garcinol significantly decreased the expression level of AKTp-Thr308 in HGC-27 cells, an effect that was abrogated with SC79 treatment (Fig. 5B). The inhibitory effect of garcinol on cell migration (Fig. 5C and E) and invasion (Fig. 5D and F) was also abrogated following treatment with SC79. The effects of SC79 on garcinol-induced apoptosis of HGC-27 cells were investigated using Hoechst 33258 staining and flow cytometry analysis. The results revealed that SC79 significantly decreased the number of apoptotic cells compared with the garcinol only-treated group (Fig. 6A-D). 
A

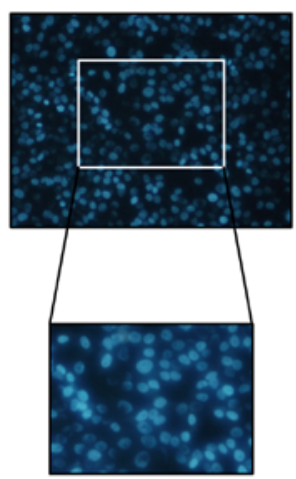

Control

B

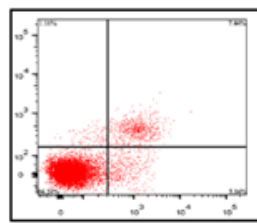

Control
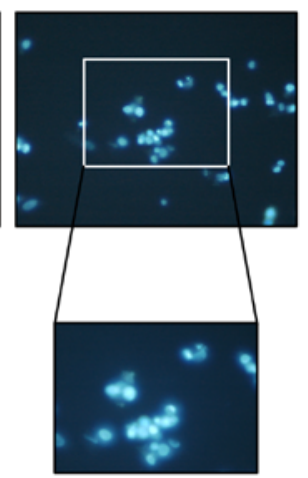

Garcinol

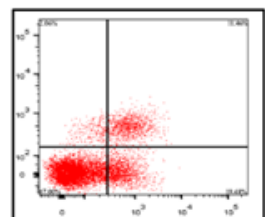

Garcinol

C

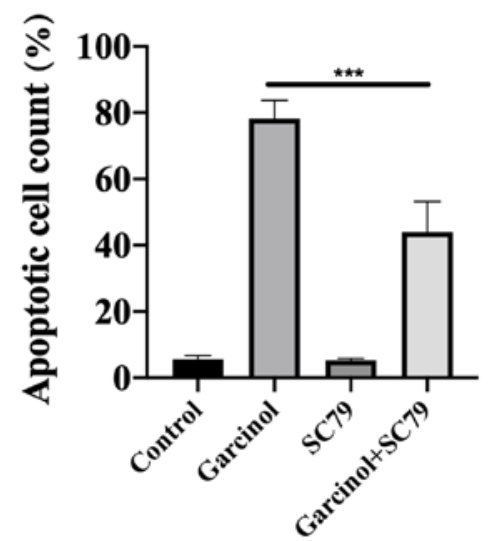

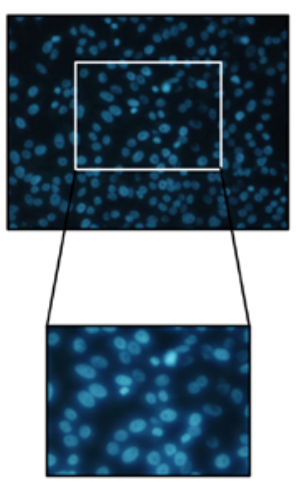

SC79

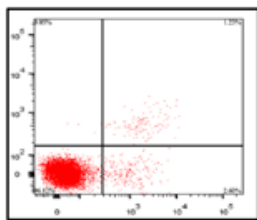

SC79

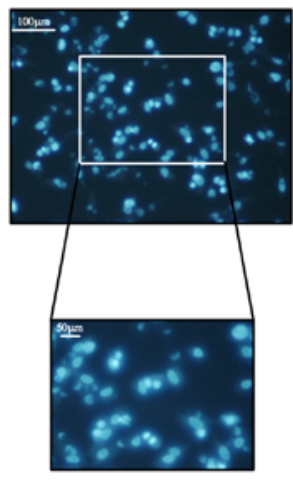

Garcinol +SC79

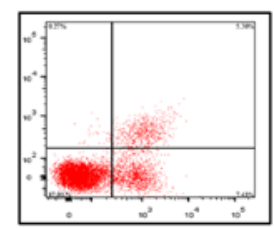

Garcinol+SC79

D

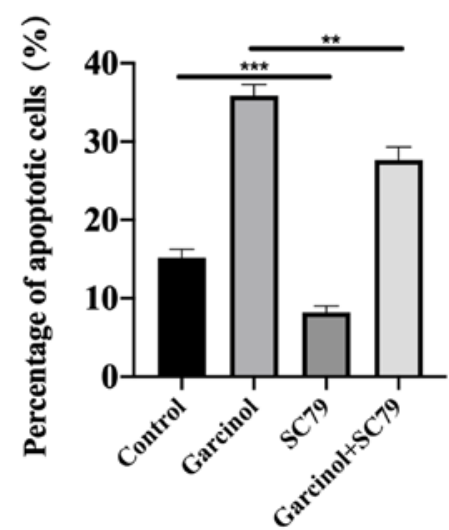

Figure 6. SC79, a specific AKT agonist, rescues garcinol-induced apoptosis in HGC-27 cells. (A) Hoechst 33258 staining was performed to analyze apoptosis. (B) Annexin V-FITC/PI staining was used to assess the apoptotic ratio of HGC-27 cells in the different groups after 48 h. (C) Apoptotic cell counts of each intervention group were compared with the vacant control group. ${ }^{* * *} \mathrm{P}<0.005$. (D) Percentages of apoptotic cells of each group were compared with those of the vacant control group at $48 \mathrm{~h} .{ }^{* * *} \mathrm{P}<0.01,{ }^{* * *} \mathrm{P}<0.005$.

\section{Discussion}

$\mathrm{GC}$ is one of the most common malignant diseases (1) and is responsible for the second largest number of cancer-associated mortalities. There are major challenges in developing effective therapeutic strategies for advanced GC, and novel therapies are urgently required.

Garcinol is a bioactive phytochemical with anti-carcinogenic properties. Previous studies have demonstrated that garcinol decreases proliferation and induces apoptosis in numerous tumor cells $(18,19,26,27)$. The anti-neoplastic activities of garcinol are reported to occur via a variety of tumor-associated signaling pathways. Garcinol inhibited autophagy and increased apoptosis of prostate cancer cells by regulating the PI3K/AKT signaling pathway (23). Furthermore, garcinol suppressed the progression of pancreatic (28) and breast (29) carcinomas by mediating NF- $\mathrm{KB}$ signaling and down-regulated the growth of hepatocellular carcinoma cells by modulating STAT3 (30). However, to the best of our knowledge, the effects and underlying mechanisms of garcinol in GC cells have not been previously reported. The results obtained in the present study revealed that garcinol significantly reduced the viability and colony formation ability of GC cell line HGC-27 in a dose-dependent manner. Garcinol resulted in a significant, dose-dependent decrease in the migration and invasion of HGC-27 cells, which was accompanied by an increase in apoptosis. Additionally, the percentage of HGC-27 cells in the G0/G1 phase was significantly increased while the percentage in the $S$ phase was significantly decreased following treatment with garcinol, implying significant cell cycle arrest. The G0/G1 phase is essential for DNA replication and cell division, while a sustained G1 block may result in apoptosis in HGC-27 cells (31-33). Therefore, garcinol may serve as a potential therapeutic agent for GC.

Tumor growth and metastasis are crucial steps in tumorigenesis. Previous studies have indicated that mTOR is expressed in $60-80 \%$ of gastric adenocarcinomas $(34,35)$. The regulation 
of cyclin D1 production by mTOR is the primary mechanism by which mTOR mediates cell proliferation (36). Moreover, overexpression of cyclin D1 promotes the G1-S cell cycle transition and accelerates the GC tumorigenesis (37). Therefore, mTOR/cyclin D1 inhibitors may suppress tumor proliferation. The present study revealed that garcinol decreased the protein expression of mTOR, mTOR ${ }^{\mathrm{p}-\mathrm{Ser} 248}$ and cyclin D1 in HGC-27 cells in a dose-dependent manner, suggesting that it suppresses the viability and proliferation of GC cells. Moreover, garcinol significantly reduced the expression of MMP-2/9 proteins in a dose-dependent manner. As proteolytic enzymes, the MMP family participates in the degradation of the extracellular matrix and MMP-2/9 proteins play important roles in invasion and angiogenesis in malignant tumors (38). The present study revealed that garcinol may inhibit the proliferation and extravasation of gastric carcinoma cells, thereby exerting anti-neoplastic effects and decreasing the rate of malignant progression.

A dynamic balance between cell proliferation and death is necessary to maintain homeostasis. Cancer cells are characterized by their ability to evade tumor suppressors and cell death and to sustain proliferative signaling and replication, thus activating invasion and metastasis (39). Apoptosis appears to be attenuated in numerous malignancies, thus enabling tumor cells to resist cell death and to proliferate. Apoptosis is regulated by the proapoptotic- and anti-apoptotic Bcl-2 family members (40). The upregulation of BAX and downregulation of Bcl-2 increases apoptosis. In agreement with this concept, the results obtained in the present study revealed that garcinol increased HGC-27 cell apoptosis by down-regulating Bcl-2 and an up-regulating BAX in a dose-dependent manner. These results indicated that garcinol may induce programed cell death in GC and may serve as a promising therapeutic agent.

The mechanism underlying the anti-tumor effects of garcinol may be attributed to the modulation of the PI3K/AKT signaling pathway. The PI3K/AKT signaling pathway is closely associated with neoplastic transformation, since the activation of AKT is known to drive cellular growth, differentiation and survival (41-43). Phosphorylated AKT enters the nucleus and activates mTOR and downstream signaling, which subsequently accelerates neoplasm progression (44). Previous studies suggested that the $\mathrm{PI} 3 \mathrm{~K} / \mathrm{AKT} / \mathrm{mTOR}$ pathway is activated in gastric tumor tissues, compared with non-tumor tissues $(14,35,45)$, indicating that targeted blocking of this pathway may be able to suppress gastric tumorigenesis. Additionally, activated AKT promotes the expression of MMPs, and reduces the binding of the Bcl-2/XL-associated death (BAD) gene promoter to $\mathrm{Bcl}-2 / \mathrm{XL}(46,47)$, to increase the invasion and decrease the apoptosis of gastric carcinoma cells. The present study revealed that the protein levels of $\mathrm{AKT}^{\mathrm{p} \text {-Thr308 }}, \mathrm{AKT}^{\mathrm{p}-\mathrm{Ser} 473}$ and mTOR $^{\mathrm{p}-\mathrm{Ser} 2448}$ in HGC-27 cells decreased following treatment with garcinol in a dose-dependent manner. These aforementioned results suggested that garcinol exerts its antitumor effects in HGC-27 cells by inhibiting the PI3K/AKT signaling pathway. In order to further validate these findings, rescue experiments using SC79, a specific agonist of AKT, were performed. The results revealed that SC79 abrogated the garcinol-induced inhibitory effects on HGC-27 cells, which further consolidated the evidence garcinol inhibits the PI3K/AKT signaling pathway.

In conclusion, the present study demonstrated that garcinol suppresses tumorigenesis in GC by decreasing cell proliferation, inhibiting cell invasion and migration and promoting cell apoptosis. Further investigation revealed that garcinol is likely to exhibit these effects by inhibiting the PI3K/AKT signaling pathway and downregulating the expression of Cylin D1, MMP2, MMP9 in HGC-27 cells, which can be rescued by SC79, a specific agonist of AKT, at the cellular level (Fig. S1). Therefore, garcinol may play crucial roles in GC and may serve a novel therapeutic agent.

\section{Acknowledgements}

Not applicable.

\section{Funding}

The present study was supported by The National Natural Science Foundation of China grant (grant nos. 81670472, 81700502 and 81800538), The Medical Health Scientific Project of Zhejiang (grant no. 2019KY226) and The Technology Development Research Plan of Shaoxing (grant no. 2018C30097).

\section{Availability of data and materials}

All data generated and/or analyzed during this study are included in this published article.

\section{Authors' contributions}

AM, CG and XW conceived and designed the research. YZ, CG, $\mathrm{XZ}$ performed the experiments and analyzed the data. YZ wrote the manuscript. All authors read and approved the final manuscript.

\section{Ethics approval and consent to participate}

Not applicable.

\section{Patient consent for publication}

Not applicable.

\section{Competing interests}

The authors declare that they have no competing interests.

\section{References}

1. Torre LA, Bray F, Siegel RL, Ferlay J, Lortet-Tieulent J and Jemal A: Global cancer statistics, 2012. CA Cancer J Clin 65: 87-108, 2015.

2. Van Cutsem E, Sagaert X, Topal B, Haustermans K and Prenen H: Gastric cancer. Lancet 388: 2654-2664, 2016.

3. Orditura M, Galizia G, Sforza V, Gambardella V, Fabozzi A, Laterza MM, Andreozzi F, Ventriglia J, Savastano B Mabilia A, et al: Treatment of gastric cancer. World J Gastroenterol 20: 1635-1649, 2014.

4. Karimi P, Islami F, Anandasabapathy S, Freedman ND and Kamangar F: Gastric cancer: Descriptive epidemiology, risk factors, screening, and prevention. Cancer Epidemiol Biomarkers Prev 23: 700-713, 2014. 
5. Song Z, Wu Y, Yang J, Yang D and Fang X: Progress in the treatment of advanced gastric cancer. Tumour Biol 39: $1010428317714626,2017$.

6. Wu WK, Cho CH, Lee CW, Fan D, Wu K, Yu J and Sung J: Dysregulation of cellular signaling in gastric cancer. Cancer Lett 295: 144-153, 2010.

7. Fresno Vara JA, Casado E, de Castro J, Cejas P, Belda-Iniesta C and González-Barón M: PI3K/Akt signalling pathway and cancer. Cancer Treat Rev 30: 193-204, 2004.

8. Hennessy BT, Smith DL, Ram PT, Lu Y and Mills GB: Exploiting the PI3K/AKT pathway for cancer drug discovery. Nat Rev Drug Discov 4: 988-1004, 2005.

9. Evan GI and Vousden KH: Proliferation, cell cycle and apoptosis in cancer. Nature 411: 342-348, 2001.

10. Zhang J, Xu J, Dong Y and Huang B: Down-regulation of HIF-1 $\alpha$ inhibits the proliferation, migration, and invasion of gastric cancer by inhibiting PI3K/AKT pathway and VEGF expression. Biosci Rep 38: BSR20180741, 2018.

11. Gupta AK, Cerniglia GJ, Mick R, Ahmed MS, Bakanauskas VJ, Muschel RJ and McKenna WG: Radiation sensitization of human cancer cells in vivo by inhibiting the activity of PI3K using LY294002. Int J Radiat Oncol Biol Phys 56: 846-853, 2003.

12. Ao R, Guan L, Wang Y and Wang JN: Silencing of COL1A2, COL6A3, and THBS2 inhibits gastric cancer cell proliferation, migration, and invasion while promoting apoptosis through the PI3k-Akt signaling pathway. J Cell Biochem 119: 4420-4434, 2018

13. Kumari S, Puneet, Prasad SB, Yadav SS, Kumar M, Khanna A, Dixit VK, Nath G, Singh S and Narayan G: Cyclin D1 and cyclin E2 are differentially expressed in gastric cancer. Med Oncol 33: 40, 2016.

14. Riquelme I, Tapia O, Espinoza JA, Leal P, Buchegger K, Sandoval A, Bizama C, Araya JC, Peek RM and Roa JC: The Gene expression status of the PI3K/AKT/mTOR pathway in gastric cancer tissues and cell lines. Pathol Oncol Res 22: 797-805, 2016

15. Zhou R, Xu L, Ye M, Liao M, Du H and Chen H: Formononetin inhibits migration and invasion of MDA-MB-231 and 4T1 breast cancer cells by suppressing MMP-2 and MMP-9 through PI3K/AKT signaling pathways. Horm Metab Res 46: 753-760, 2014.

16. Zhou H, Wu J, Wang T, Zhang X and Liu D: CXCL10/CXCR3 axis promotes the invasion of gastric cancer via PI3K/AKT pathway-dependent MMPs production. Biomed Pharmacother 82: 479-488, 2016.

17. Chang F, Lee JT, Navolanic PM, Steelman LS, Shelton JG, Blalock WL, Franklin RA and McCubrey JA: Involvement of PI3K/Akt pathway in cell cycle progression, apoptosis, and neoplastic transformation: A target for cancer chemotherapy. Leukemia 17: 590-603, 2003.

18. Liu C, Ho PC, Wong FC, Sethi G, Wang LZ and Goh BC: Garcinol: Current status of its anti-oxidative, anti-inflammatory and anti-cancer effects. Cancer Lett 362: 8-14, 2015.

19. Saadat N and Gupta SV: Potential role of garcinol as an anticancer agent. J Oncol 2012: 647206, 2012.

20. Oike T, Ogiwara H, Torikai K, Nakano T, Yokota J and Kohno T: Garcinol, a histone acetyltransferase inhibitor, radiosensitizes cancer cells by inhibiting non-homologous end joining. Int J Radiat Oncol Biol Phys 84: 815-821, 2012.

21. Yamaguchi F, Saito M, Ariga T, Yoshimura Y and Nakazawa H: Free radical scavenging activity and antiulcer activity of garcinol from garcinia indica fruit rind. J Agric Food Chem 48: 2320-2325, 2000

22. Liao CH, Sang S, Ho CT and Lin JK: Garcinol modulates tyrosine phosphorylation of FAK and subsequently induces apoptosis through down-regulation of Src, ERK, and Akt survival signaling in human colon cancer cells. J Cell Biochem 96: 155-169, 2005.

23. Wang Y, Tsai ML, Chiou LY, Ho CT and Pan MH: Antitumor activity of garcinol in human prostate cancer cells and xenograft mice. J Agric Food Chem 63: 9047-9052, 2015.

24. Aggarwal S and Das SN: Garcinol inhibits tumour cell proliferation, angiogenesis, cell cycle progression and induces apoptosis via NF-kB inhibition in oral cancer. Tumor Biology 37 7175-7184, 2016

25. Jo H, Mondal S, Tan D, Nagata E, Takizawa S, Sharma AK, Hou QM, Shanmugasundaram K, Prasad A, Tung JK, et al: Small molecule-induced cytosolic activation of protein kinase Akt rescues ischemia-elicited neuronal death. Proc Natl Acad Sci USA 109: 10581, 2012.

26. Zhou XY, Cao J, Han CM, Li SW, Zhang C, Du YD, Zhou QQ, Zhang XY and Chen X: The C8 side chain is one of the key functional group of Garcinol for its anti-cancer effects. Bioorg Chem 71: 74-80, 2017.
27. Ahmad A, Sarkar SH, Aboukameel A, Ali S, Biersack B, Seibt S, Li YW, Bao B, Kong D, Banerjee S, et al: Anticancer action of garcinol in vitro and in vivo is in part mediated through inhibition of STAT-3 signaling. Carcinogenesis 33: 2450-2456, 2012.

28. Parasramka MA and Gupta SV: Garcinol inhibits cell proliferation and promotes apoptosis in pancreatic adenocarcinoma cells. Nutr Cancer 63: 456-465, 2011.

29. Ahmad A, Wang Z, Ali R, Maitah MY, Kong DJ, Banerjee S, Padhye S and Sarkar FH: Apoptosis-inducing effect of garcinol is mediated by NF-kappaB signaling in breast cancer cells. J Cell Biochem 109: 1134-1141, 2010.

30. Sethi G, Chatterjee S, Rajendran P, Li F, Shanmugam MK, Wong KF, Kumar AP, Senapati P, Behera AK, Hui KM, et al: Inhibition of STAT3 dimerization and acetylation by garcinol suppresses the growth of human hepatocellular carcinoma in vitro and in vivo. Molecular Cancer 13: 66, 2014

31. Hammarton TC, Engstler M and Mottram JC: The Trypanosoma brucei Cyclin, CYC2, is required for cell cycle progression through G1 phase and for maintenance of procyclic form cell morphology. J Biol Chem 279: 24757-24764, 2004.

32. Arand J and Sage J: G1 cyclins protect pluripotency. Nat Cell Biol 19: 149-150, 2017

33. Gao Z, Zhu M, Wu Y, Gao $\mathrm{P}$, Qin $\mathrm{Z}$ and Wang $\mathrm{H}$ : Interferon-lambda1 induces G1 phase cell cycle arrest and apoptosis in gastric carcinoma cells in vitro. Oncol Rep 32: 199-204, 2014.

34. Lang SA, Gaumann A, Koehl GE, Seidel U, Bataille F, Klein D, Ellis LM, Bolder U, Hofstaedter F, Schlitt HJ, et al: Mammalian target of rapamycin is activated in human gastric cancer and serves as a target for therapy in an experimental model. Int J Cancer 120: 1803-1810, 2007.

35. Feng W, Brown RE, Trung CD, Li W, Wang LW, Khoury T, Alrawi S, Yao J, Xia K and Tan D: Morphoproteomic profile of mTOR, Ras/Raf Kinase/ERK, and NF- $\mathrm{B}$ pathways in human gastric adenocarcinoma. Ann Clin Lab Sci 38: 195-209, 2008.

36. Advani SH: Targeting mTOR pathway: A new concept in cancer therapy. Indian J Med Paediatr Oncol 31: 132-136, 2010.

37. Resnitzky D and Reed SI: Different roles for cyclins D1 and E in regulation of the G1-to-S transition. Mol Cell Biol 15: 3463 , 1995.

38. Egeblad M and Werb Z: New functions for the matrix metalloproteinases in cancer progression. Nat Rev Cancer 2: 161-174, 2002.

39. Hanahan D and Weinberg RA: Hallmarks of cancer: The next generation. Cell 144: 646-674, 2011

40. Adams JM and Cory S: The Bcl-2 apoptotic switch in cancer development and therapy. Oncogene 26: 1324-1337, 2007.

41. Zhou SY, Baltimore D, Cantley LC, Kaplan DR and Franke TF. Interleukin 3-dependent survival by the Akt protein kinase. Proc Natl Acad Sci USA 94: 11345-11350, 1997.

42. Geng W and Zhang HY: Research on the mechanism of HP mediated PI3K/AKT/GSK3 $\beta$ pathways in gastric cancer. Eur Rev Med Pharmacol Sci 21 (Suppl 3): S33-S37, 2017.

43. Nagy TA, Frey MR, Yan F, Israel DA, Polk DB and Peek RM Jr: Helicobacter pylori regulates cellular migration and apoptosis by activation of phosphatidylinositol 3-kinase signaling. J Infect Dis 199: 641-651, 2009.

44. Morita M, Gravel SP, Hulea L, Larsson O, Pollak M, St-Pierre J and Topisirovic I: mTOR coordinates protein synthesis, mitochondrial activity and proliferation. Cell Cycle 14: 473-480, 2015.

45. Tapia O, Riquelme I, Leal P, Sandoval A, Aedo S, Weber H, Letelier P, Bellolio E, Villaseca M, Garcia P and Roa JC: The $\mathrm{PI} 3 \mathrm{~K} / \mathrm{AKT} / \mathrm{mTOR}$ pathway is activated in gastric cancer with potential prognostic and predictive significance. Virchows Archiv 465: 25-33, 2014.

46. Mayer IA and Arteaga CL: The PI3K/AKT pathway as a target for cancer treatment. Annu Rev Med 67: 11-28, 2016.

47. Cheng TC, Din ZH, Su JH, Wu YJ and Liu CI: Sinulariolide suppresses cell migration and invasion by inhibiting matrix metalloproteinase-2/-9 and urokinase through the PI3K/AKT/mTOR signaling pathway in human bladder cancer cells. Mar Drugs 15: E238, 2017

This work is licensed under a Creative Commons Attribution-NonCommercial-NoDerivatives 4.0 International (CC BY-NC-ND 4.0) License. 